\title{
Summer Vacation Placements - creating internships that work
}

Author: Natalie Lewis, University Hospitals Birmingham NHS Foundation Trust

Background: Unpaid pharmacy placements have recently come under fire from students who have found placements to be unfair with some providers not prepared to take on unpaid students due to a recent employment tribunal hearing. This has resulted in a reduction in the duration and number of vacation placements available; whilst demand for unpaid experience has spiralled.

Method: During summer 2013 one UK hospital expanded its vacation program and contracted 20 students for 4 week placements consisting of strict 50:50 split of provision of education and training activities in return for involvement in departmental activities. All placements were supported by a timetable, a mentor and a workbook with competency assessments for particular activities. Audit and project work was also provided. Those completing the placement to a satisfactory level were awarded a certificate.

Results: $96 \%$ of the contracted weeks were completed giving a total student input of approximately 2888 hours with $50 \%$ (1444 hours) directed to departmental work including audits and counselling checklist formation. The $4 \%$ not completed was due to sickness and interview attendance. The initiative was evaluated by informal student interview, feedback from pharmacy staff and review of student work.

$100 \%$ of participants stated that the split of time was equitable, that audit and project work carried educational merit, and they would apply for future hospital placements or pre-registration positions. No staff declared any burden produced by the presence of the students in their areas in relation to student output. All work produced was seen to be at $(30 \%)$ or above $(70 \%)$ the level expected.

Conclusion: It is possible to produce equitable pharmacy internships which provide benefit to the trust and the student in a cost neutral manner. Students appreciate the opportunity to learn in a practical environment and can attach learning objectives to many types of departmental activity. 